\title{
Correlation between serum myoglobin and thyroid status in myasthenia gravis
}

\author{
WOLFGANG R KIESSLING \\ From the Department of Neurology, University of Würzburg, FRG
}

SUMMARY In 52 patients with myasthenia gravis serum myoglobin showed a significant inverse correlation to circulating thyroxine and triiodothyronine levels. The highest myoglobin concentration $(240 \mathrm{ng} / \mathrm{ml})$ was found in a myasthenia gravis patient with hypothyroidism. Slightly elevated myoglobin $(54-60 \mathrm{ng} / \mathrm{ml})$ was measured in four euthyroid myasthenic patients. The data suggest that a concomitant hypothyroid state must be excluded whenever high myoglobin levels are found in myasthenia gravis.

The recent introduction of sensitive myoglobin radioimmunoassays has proved that this method is useful not only in the early diagnosis of myocardial infarction but also in assessment of skeletal muscle damage. ${ }^{2}$ Conflicting data were found in myasthenia gravis. It is reported that $38-54 \%$ of myasthenia gravis patients had elevated myogloblin levels ${ }^{3} 4$ whereas other investigators ${ }^{5}$ found normal levels in all of their myasthenic patients tested. We have reevaluated this problem taking into account that myasthenia gravis may be associated with thyroid disorders such as hyperthyroidism or hypothyroidism $^{6} 7$ which are known to cause altered serum myoglobin levels. ${ }^{8}$

\section{Patients and methods}

The study was made on 52 myasthenia gravis patients ( 20 men and 32 women aged 14-70, average $33 \cdot 3$ years). Generalised myasthenia gravis has been established in all of them by history, physical examination, decremental responses on repetitive nerve stimulation and improvement of muscle strength with anticholinesterase agents. Thirty-six patients had treatment with $360-720 \mathrm{mg}$ pyridostigmin bromide retard per day (regimen A) and 16 were treated with $360-720 \mathrm{mg}$ pyridostigmin bromide retard and azathioprine $2 \mathrm{mg} / \mathrm{kg} /$ day (regimen $\mathrm{B}$ ). The thyroid status was evaluated on the basis of triiodo-

Address for reprint requests: Dr WR Kiessling, Neurologische Universitätsklinik, Josef-Schneider-Str 11, D-8700 Würzburg, FRG.

Received 18 July 1981

Accepted 27 August 1981 thyronine (T3), thyroxine (T4), thyroxine binding globulin (TBG) and thyrotropin (TSH) radioimmunoassays (Henning $\mathrm{GmbH}$, Berlin, Germany). Normal ranges established in our laboratory are: $\mathrm{T} 440-130 \mathrm{ng} / \mathrm{ml}$, TBG $13-30 \mathrm{mg} / \mathrm{ml}$, T4/TBG $2 \cdot 2-5 \cdot 4$, T3 $0 \cdot 70-2 \cdot 0 \mathrm{ng} / \mathrm{ml}$, $\mathrm{TSH}<0 \cdot 3-4 \cdot 0 \mu \mathrm{U} / \mathrm{ml}$. The thyrotropin releasing hormone (TRH) test was applied additionally: at zero time $200 \mu \mathrm{g}$ TRH (Relefact TRH, Hoechst, Frankfurt, Germany) was injected intravenously. Blood samples were drawn at 0 and $30 \mathrm{~min}$. A normal TSH response ( $\Delta \mathrm{TSH})$ after TRH injection is defined as $\Delta \mathrm{TSH}>1.5 \mu \mathrm{U} / \mathrm{ml}$, but not $>$ $24.0 \mu \mathrm{U} / \mathrm{ml}$. Serum myoglobin was measured by a commercial radioimmunoassay (Daiichi Radioisotope Laboratories, Tokyo, Japan). Each sample was assayed in duplicate. The normal values for serum myoglobin in 109 healthy subjects were $31 \cdot 2 \mathrm{ng} / \mathrm{ml} \pm 24 \cdot 0$ (mean \pm 2 SD) for men and $22.1 \mathrm{ng} / \mathrm{ml} \pm 22.0$ (mean $\pm 2 \mathrm{SD}$ ) for women. ${ }^{5}$ Serum creatine kinase (CK) activity was determined in a semiautomated photometer system using monotest CK NAC aktiviert (Boehringer $\mathrm{GmbH}$, Mannheim, Germany). Normal range: men 10-80 U/l, women 10-70 U/1.

The following statistical tests were performed: examination for normal distribution, U-test (Wilcoxon's test), mean values \pm standard deviation (SD), linear regression analysis, $r=$ correlation coefficient, limit of significance $\mathrm{p}<0.05$.

\section{Results}

Amongst our myasthenia gravis patients one patient was hypothyroid. The TSH response after TRH was exaggerated $(\Delta \mathrm{TSH} 31.0 \mu \mathrm{U} / \mathrm{ml})$, T4/TBG was 0.66 , T3 was $0.7 \mathrm{ng} / \mathrm{ml}$ and the basal TSH was $11.5 \mu \mathrm{U} / \mathrm{ml}$. Three patients had concomitant hyperthyroidism. 
This diagnosis was made on the basis of moderate endocrine eye disease, elevated T4/TBG or T3 (or both), and a blocked TSH response after TRH. Forty-eight patients were euthyroid as judged by normal thyroid function tests.

Hypermyoglobinaemia $(240 \mathrm{ng} / \mathrm{ml})$ associated with an increased CK activity $(220 \mathrm{U} / \mathrm{l})$ was found in the hypothyroid patient whereas borderline-elevated myoglobin levels $(54-60 \mathrm{ng} / \mathrm{ml})$ were measured both in two euthyroid male and two euthyroid female patients. In these patients normal CK activities were present. Thirty-five of our euthyroid patients had regimen $A$ and 13 regimen $B$. The mean serum myoglobin levels of the first group $(25.8 \pm 14.4 \mathrm{ng} / \mathrm{ml})$ were not different from those of the patients receiving additional immunosuppressive treatment $(26 \cdot 1 \pm$ $15.8 \mathrm{ng} / \mathrm{ml}), \mathrm{p}(\mathrm{U})>0.05$. Linear regression analysis including the data of all patients showed an inverse correlation not only between myoglobin and T4/TBG but also between myoglobin and T3 (fig).

\section{Discussion}

Involvement of skeletal muscles in thyroid diseases is not uncommon being manifested as endocrine eye disease, thyrotoxic myopathy, thyrotoxic periodic paralysis or myopathy due to myxoedema.9 About $70 \%$ of patients with overt hypothyroidism show highly elevated CK activities ${ }^{10} 11$ and recent investigations ${ }^{8}$ have shown a concomitant increase of serum myoglobin levels. Our study in myasthenia gravis patients confirms the relationship of circulating myoglobin levels and the concentration of circulating T3 and T4. Contrary to other investigators we found abnormal myoglobin levels only in five of 52 myasthenia gravis patients $(9.6 \%)$. In one case hypermyoglobinaemia could be related to hypothyroidism which was additionally accompanied by an increased CK activity. Four myasthenia gravis patients with slightly elevated myoglobin but normal CK activities had T4 levels within the lower range of normality and T3 showed analogous conditions in three cases.

We believe that myasthenia gravis may be associated with a myoglobin increase. Although myoglobin has been suggested as a more sensitive indicator of muscle disease than CK the practical value of myoglobin determination in myasthenia gravis appears to be questionable as long as the thyroid status is not evaluated.

This investigation was supported by Henning $\mathrm{GmbH}$, Berlin. We are grateful to Dr Kellermann, Byk-Mallinckrodt, Dietzenbach, Germany, for providing the myoglobin-RIA kits. Statistical advice

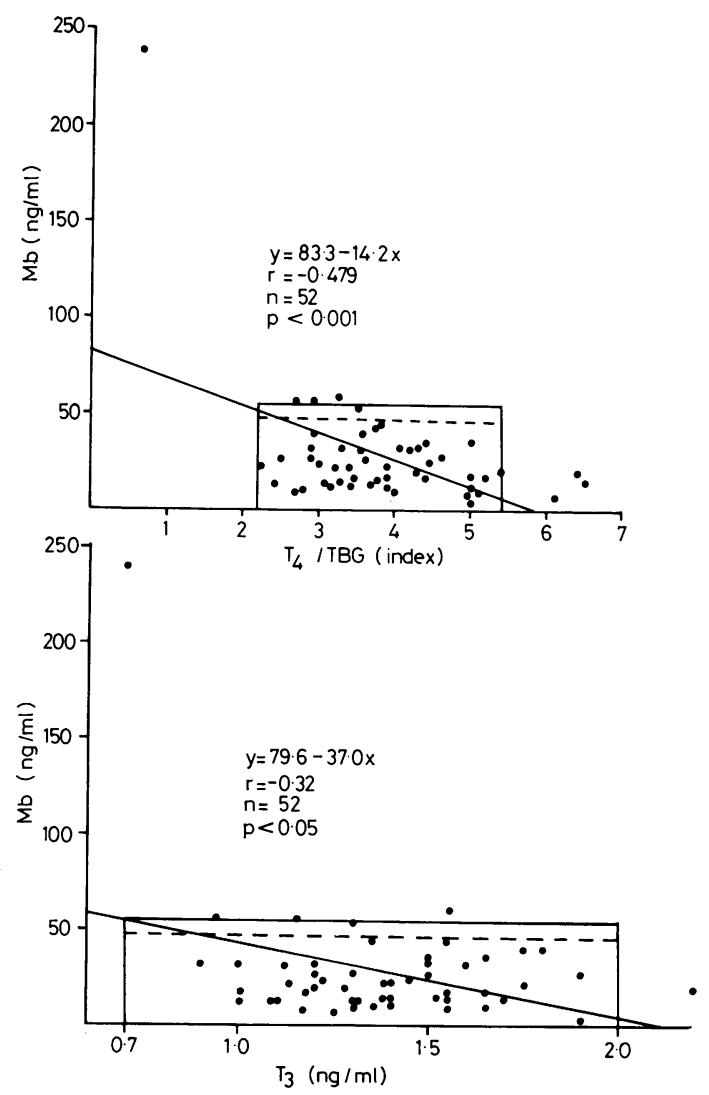

Figure Serum myoglobin in 52 patients with myasthenia gravis: (a) relationship to thyroxine (T4)/thyroxine binding globulin (TBG), (b) relationship to triiodothyronine (T3). Upper limits of serum Mb for men (- $\longrightarrow)$ and women (-- - ).

was kindly given by Dr Imme Haubitz, Rechenzentrum der Universität, Würzburg.

\section{References}

${ }^{1}$ Hische EAH, van der Heim HJ. The significance of serum myoglobin in neuromuscular diseases. $J$ Neurol Sci 1979;43:243-51.

${ }^{2}$ Miyoshi K, Saito S, Kawai H, et al. Radioimmunoassay for human myoglobin: method and results in patients with skeletal muscle and myocardial disorders. $J$ Lab Clin Med 1978;92:341-52.

${ }^{3}$ Askmark H, Osterman PO, Roxin LE. Venge P. Radioimmunoassay of serum myoglobin in neuromuscular diseases. J Neurol Neurosurg Psychiatry 1981;44:68-72.

${ }^{4}$ Nishikai M, Reichlin M. Radioimmunoassay of serum myoglobin in polymyositis and other conditions. Arthritis Rheum 1977;20:1514-8.

${ }^{5}$ Kiessling WR, Ricker K, Pflughaupt KW, Mertens HG, 
Haubitz I. Serum myoglobin in primary and secondary skeletal muscle disorders. J Neurol 1981;224: 229-33.

"Ossermann KE, Tsairis P, Weiner LB. Myasthenia gravis and thyroid disease: clinical and immunological correlation. J Mt Sinai Hosp 1967;34:469-81.

' Simpson JF, Westerberg MR, Magee KR. Myasthenia gravis. Acta Neurol Scand 1966;42:5-27.
${ }^{8}$ Kasai K. Serum myoglobin level in altered thyroid states. J Clin Endocrinol Metab 1979;48:1-4.

${ }^{9}$ Bradley WG, Walton JN. Neurologic manifestations of thyroid disease. Postgrad Med 1971;50:118-21.

${ }^{10}$ Graig FA, Ross G. Serum creatine-phosphokinase in thyroid disease. Metabolism $1963 ; 12: 57-9$.

${ }^{11}$ Griffith PD. Creatinephosphokinase levels in hypothyroidism. Lancet 1963;1:894. 